\title{
Functional properties of edible seaweeds and its use for value addition of foods
}

Received: 06.08.2016; Accepted: 26.11.2016

See end of the paper for authors' affiliations

\section{T. AMARAVATHI}

Department of Food Science and

Nutrition, Home Science College and

Research Institute, Tamil Nadu

Agricultural University, MADURAI

(T.N.) INDIA

Email : amarfsn@gmail.com

\begin{abstract}
Seaweeds, one of the important marine living resources could be termed as the futuristically promising plants. These plants have been a source of food, feed and medicine in the orient as well as in the west, since ancient times. Although, seaweeds in India are used for industrial production of agar and alginate and as a fertilizer, it is yet to be utilized on a large scale for various purposes, which is not being done, due to lack of its awareness among the Indian populace. In order to harness the rich potential of seaweeds in India, the present limited use needs to be diversified into other contemporary areas of application. Being a plant of unique structure and biochemical composition, seaweed could be exploited for its multi-functional properties in the form of food, energy, medicine and cosmetics. In addition to the comprehensive view on its uses, the article also calls for the need to implement biotechnological tools for sustainable management of seaweed resources. All in all, an attempt has been made to highlight the prospects of seaweed in India in the modern context.
\end{abstract}

KEY WORDS: Edible seaweed, Value addition, Functional properties

- HOW TO CITE THIS PAPER : Amaravathi, T. and Parimalam, P. (2016). Functional properties of edible seaweeds and its use for value addition of foods. Asian J. Home Sci., 11 (2) : 450-452, DOI: 10.15740/ HAS/AJHS/11.2/450-452.
$\mathrm{W}$ ithin the traditional Japanese diet, seaweeds are commonly used as sushi wrappings, seasonings, condiments and vegetables and can thus constitute between 10 per cent and 25 per cent of food intake of most Japanese (Ortiz et al., 2006). Marine macroalgae, or seaweeds as they are more commonly known, are one of the nature's most biologically active resources. It is commonly classified into three main groups based on their pigmentation such as Phaeophyta (brown seaweeds), Chlorophyta (green seaweeds) and Rhodophyta (red seaweeds). According to Khan and Satam (2003) the production of total seaweeds in India in 2000 was approximately 600,000 tons (wet weight). Every year about 7.5-8 million tons of wet seaweeds are being produced along the coastal regions world wide, the values of which was not realised in the past (Rao and Mantri, 2006).

They possess a wealth of bioactive compounds. In fact, seaweeds have been aptly called the medicinal food of $21^{\text {st }}$ century. Seaweeds are nature's most complete and balanced nutrient food source. The compounds isolated from marine macroalgae have demonstrated various biological activities, such as antibacterial activity, antioxidant potential, anti-inflammatory properties, anti-coagulant activity, anti-viral activity and apoptotic activity. As a result, seaweeds-derived 